\title{
The Dilemma of Balancing Design for Impact Sound with Environmental Performance in Wood Ceiling Systems-A Building Physics Perspective
}

\author{
Theresa Müller ${ }^{1, *}$, David Borschewski ${ }^{1}$, Stefan Albrecht ${ }^{2}{ }^{\mathbb{D}}$, Philip Leistner ${ }^{1,2}$ and Moritz Späh ${ }^{2}$ \\ 1 Institute for Acoustics and Building Physics IABP, University of Stuttgart, D-70569 Stuttgart, Germany; \\ david.borschewski@iabp.uni-stuttgart.de (D.B.); philip.leistner@ibp.fraunhofer.de (P.L.) \\ 2 Fraunhofer Institute for Building Physics IBP, D-70569 Stuttgart, Germany; \\ stefan.albrecht@ibp.fraunhofer.de (S.A.); moritz.spaeh@ibp.fraunhofer.de (M.S.) \\ * Correspondence: theresa.mueller@iabp.uni-stuttgart.de
}

check for updates

Citation: Müller, T.; Borschewski, D.; Albrecht, S.; Leistner, P.; Späh, M. The Dilemma of Balancing Design for Impact Sound with Environmental Performance in Wood Ceiling Systems-A Building Physics Perspective. Sustainability 2021, 13, 8715. https://doi.org/10.3390/ su13168715

Academic Editor: Luisa Molari

Received: 30 June 2021

Accepted: 31 July 2021

Published: 4 August 2021

Publisher's Note: MDPI stays neutral with regard to jurisdictional claims in published maps and institutional affiliations.

Copyright: (c) 2021 by the authors. Licensee MDPI, Basel, Switzerland. This article is an open access article distributed under the terms and conditions of the Creative Commons Attribution (CC BY) license (https:// creativecommons.org/licenses/by/ $4.0 /)$.

\begin{abstract}
Due to the high consumption of resources and energy in the construction sector, the development of resource-efficient and sustainable construction solutions is gaining increasing attention. The awareness of sustainability and resource conservation results in the interest of using natural and renewable materials in contemporary architecture. Timber construction methods offer both constructive and ecological potential for sustainable solutions. From a building physics perspective, the acoustic performance of lightweight buildings, such as those made of timber, presents a challenge. Even if standard requirements are met, the increased low-frequency sound transmission typical for light-weight construction can cause discomfort and is already the subject of questions in building physics, which are currently increasingly extending to timber construction. Within the framework of a holistic approach, this paper compares the problem of acoustic properties, design optimizations and the ecological properties of timber-frame and solid timber construction components. The comparison with heavy materials, such as concrete, shows the relation of acoustic optimization with the change of the environmental profile. In order to establish the interaction between acoustic quality of wooden ceiling constructions and their ecological characteristics, this article aims to demonstrate the potential of materials used in the building sector under ecological aspects considering a life cycle analysis.
\end{abstract}

Keywords: timber construction; wooden ceiling systems; nature-based materials; acoustic quality; life cycle assessment

\section{Introduction}

With its high consumption of resources and energy, the construction sector is one of the major sources of environmental pollution. Currently, this discipline accounts for 35\% of global energy consumption [1]. Therefore, both the reduction of resource consumption of buildings and the application of resource-efficient and sustainable material and construction solutions are gaining increasing attention and interest. In addition, the need for cost-effective and material-efficient construction is growing [2]. As a result, the use of natural and renewable materials, such as wood, has been increasing in the recent decade. This raw material has been used as a building material in traditional construction for centuries and its material properties as well as its building physics characteristics provide it with good prerequisites as a material for innovative and sustainable construction solutions [3]. Due to the increasing awareness of sustainability and resource conservation, it is therefore gaining importance in contemporary architecture [4].

In the context of building physics, acoustics are a major challenge in multi-storey timber construction and protection against noise has an important role to be considered [5]. The perceived acoustic quality in lightweight buildings is different from that in solid buildings. In particular, the transmission of low-frequency sound, such as impact sound, 
has a very high potential for disturbance in buildings made of wood which can impair user comfort [6]. The sound insulation of ceilings is based, among other aspects, on the parameters of usage and must meet defined requirements in residential buildings. Often, the acoustic requirements according to the standards do not meet the expectations of the residents. Even if the requirements of building construction standards are fulfilled, the experienced noise and vibration disturbances of the residents tend to increase [7]. The current acoustic requirements for residential buildings are based on experience in heavy weight buildings in the construction sector, as these constructions have been dominant in Europe in the past decades [8]. The description of subjective perception and the lowfrequency transmission behavior due to impact sound in multi-storey timber buildings is already subject of various acoustic questions [7,9-12]. Furthermore, the extension of the ecological consideration of materials and constructions under the aspect of holistic evaluation in the context of sustainability is becoming increasingly important.

In order to establish the relation between building-physical quality and the environmental performance, with a focus on the acoustic requirements of wooden ceiling constructions, typical timber constructions were selected and examined in more detail as an example with regard to their acoustic behaviour. Common concrete ceiling construction is used as a reference. With the aim of demonstrating the potential of the materials used in the building sector, the acoustic evaluation is extended to include ecological characteristics. Ecology and economy represent a central task of holistic and sustainable planning and design. This is the motivation for subjecting the considered systems to a life cycle analysis.

\section{Materials and Methods}

In order to quantify acoustic and ecological evaluation methods and to examine the applicability to integrative design approaches, typical ceiling constructions made from concrete and timber were investigated from which the relevant data for the evaluation are available $[7,10,13]$. The specific acoustic performance of wooden ceiling constructions is the focus of this analysis, as timber constructions tend to have higher impact sound transmission due to the inherent lower bulk density of the material [10]. By varying different construction details, components can be generated that differ in their respective building physical properties and ecological characteristic values. Depending on the requirements, the properties can be adapted to the demands, by for example changing the thickness of the components and the materials used. For the acoustic analysis, measurement data of the weighted impact sound level $L_{n, w}$ and the spectrum adaptation term $C_{I}$ from the Fraunhofer Institute for Building Physics IBP [7,10], measured with the standard tapping machine according to DIN EN ISO 10140-5 [14], was used. Further, numerical values of tested example constructions of solid wood from the component catalog according to [13] were considered. Studies at the Fraunhofer IBP have shown that when using the standard tapping machine as an impact sound source in lightweight construction, the spectrum adaptation term $C_{I}$ should be added to single-number values of the weighted impact sound level $L_{n, w}$ in an extended frequency range according to DIN EN ISO 717-2 [15] to represent walking noise appropriately $[5,7,10,12]$. In the context of this paper, the acoustic behavior of wooden ceiling constructions in the low-frequency range is investigated on the basis of typical example constructions in order to demonstrate and discuss optimization approaches and potential for improvement.

From the perspective of sustainable design of structures and buildings, the methodology of life cycle assessment (LCA) is becoming increasingly important to provide the basis for a holistic evaluation. It is the most relevant instrument for the systematic analysis of environmentally decisive impacts of products, services and processes and are standardised in the DIN EN ISO 14040 [16] and DIN EN ISO 14044 [17]. The basis for the analysis is the recording of all relevant material flows that can be assigned to a product, service or process over the entire life cycle, for example various energy sources and other raw materials, secondary products or emissions into the environment. The effects caused by these material flows are then quantified with the help of impact indicators (e.g., climate change). 
The evaluation of the environmental impacts of the investigated ceiling systems was performed using the GENERIS ${ }^{\circledR}$ [18] tool for life cycle building assessment, developed by the Fraunhofer IBP. GENERIS ${ }^{\circledR}$ enables the preparation of life cycle assessment studies in accordance with current standardization and in compliance with certification systems for sustainable buildings like the German Sustainable Building Council: DGNB and BREEAM. It also serves as decision support during the entire planning process. It uses the ÖKOBAUDAT database [19], with which the Federal Ministry of the Interior, for Building and the Interior (BMI) provides all stakeholders with a standardized database for the life cycle assessment of buildings, in compliance with DIN EN 15804 [20].

The 2020-II version of ÖKOBAUDAT was used to assess the constructions. The database contains generic and manufacturer-specific data sets. Generic data sets were used to ensure proper comparability. Due to the lack of generic data for the polystyrene board, an EPS rigid foam board from Styropor ${ }^{\circledR}$ was used. The constructions are built up by the different layers according to the structure. Each material is matched with a dataset from the database and provided with a respective end-of-life scenario.

\section{Challenges of Wooden Ceiling Constructions in an Acoustic Context}

For the acoustic comparison of wooden ceiling constructions, raw ceiling constructions made of wooden beams and solid timber are first compared on the basis of their respective evaluated impact sound level. In order to identify the specific properties of lightweight construction, the reinforced concrete construction method is also taken into consideration in this paper. To compare the impact sound levels of different constructions, it is advisable to use characteristic values such as the frequency weighted impact sound level $\mathrm{L}_{n, w}$ in combination with the spectrum adaptation term $C_{I}$ according to [15].

In the first investigation, four types of raw ceiling constructions made of timber and reinforced concrete were compared. The buildup of the three most relevant basic types are described in the following. The raw ceiling construction in timber beam construction is approximately $180 \mathrm{~mm}$ deep and the intermediate space is filled with a $100 \mathrm{~mm}$ thick insulation layer of mineral wool. On the underside, the construction is covered with wooden battens and plasterboard. The top of the beams is covered with a wood chipboard to create a plane surface [7]. The solid timber ceiling slab consists of a $140 \mathrm{~mm}$ thick cross laminated timber plate. The reinforced concrete raw construction has about the same thickness as the solid wood slab [10]. An overview of the weighted impact sound level $\mathrm{L}_{n, w}$ of selected constructions from the investigations is given in Figure 1. The weighted impact sound level of the cross laminated timber plate (V4) was calculated based on the generally valid approximate solution for plates with a mass per unit area between $35 \mathrm{~kg} / \mathrm{m}^{2}$ and $130 \mathrm{~kg} / \mathrm{m}^{2}$ according to [21,22].

It is shown that the reinforced concrete construction (V1), despite its mass, has no significant advantage compared to the wooden beam construction (V2) from an acoustic point of view. In general, it emerges that additional constructive measures are necessary for the shown variants of the raw constructions in order to optimize the acoustic behavior and to comply with the limit values according to the standard. In residential buildings, floor slabs must not exceed the limit value of $50 \mathrm{~dB}$ [23]. The impact sound level of ceiling constructions can be significantly reduced not only by a floor construction but also by means of a suspended ceiling or a combination. Possible ceiling construction improvement measures (in comparison to the abovementioned basic types) are shown schematically in Figure 2. 


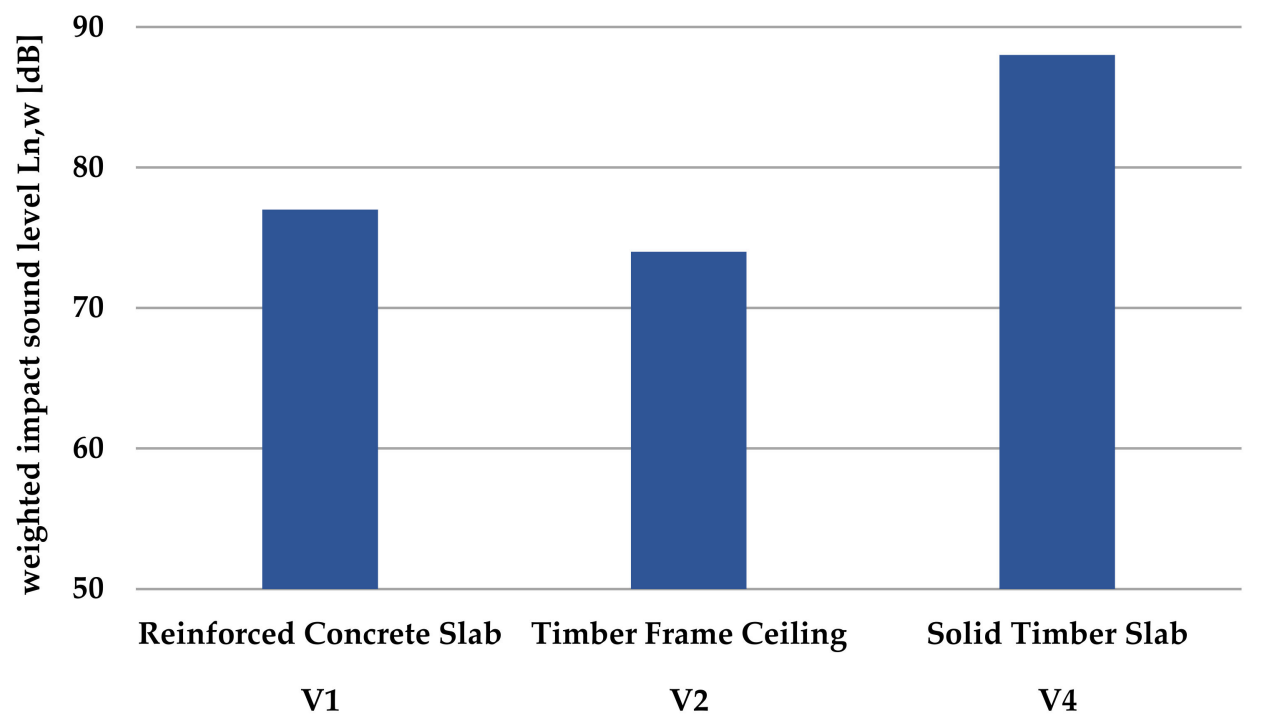

Figure 1. Weighted impact sound level $\mathrm{L}_{\mathrm{n}, \mathrm{w}}$ of selected raw ceiling constructions from the investigations $[7,10]$.
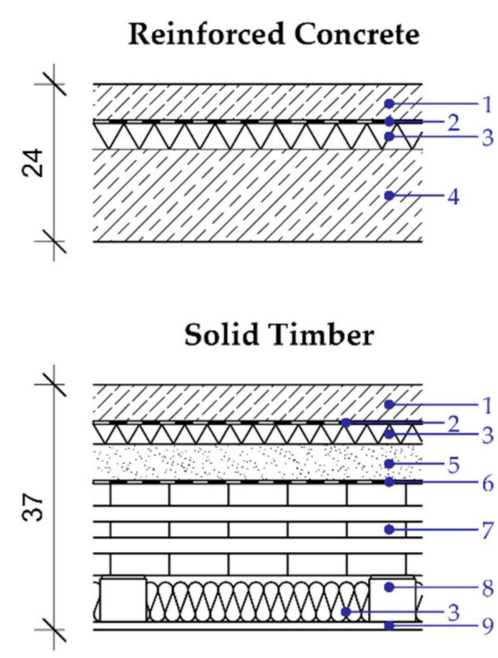

Timber Frame

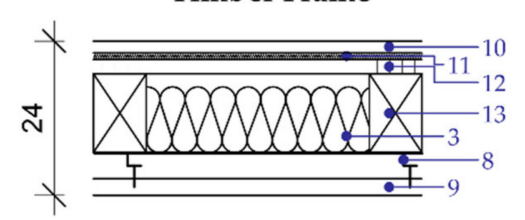

1 Cement screed Separation layer 3 Mineral wool 4 Reinforced concrete 5 Filling (unbound) 6 Protection layer 7 CLT

Figure 2. Examined ceilings including constructive measures to improve the impact sound levels based on $[7,13]$.

Further variants for the acoustic improvement of ceiling constructions considered in this paper are listed in Table 1. Here, the three mentioned raw ceiling constructions (basic types) are shown with two constructive improvement measures each. Only the most relevant results over 13 variants investigated as part of the research are shown here. The measures according to Table 1 can reduce the weighted impact sound level $L_{n, w}$ of the reinforced concrete ceiling up to $35 \mathrm{~dB}$ depending on the floor construction [7]. With timber constructions, a combination of floor construction measures and the use of a suspended ceiling has the greatest reduction effect on impact sound. Values of weighted impact sound levels of acoustically optimized floor constructions can be found in Table 2. In addition, the recommendation of combining the weighted impact sound level $\mathrm{L}_{n, w}$ and the spectrum adaptation value $C_{I}$ mentioned at the beginning is also presented in the last column, as is more correlated with the subjective perception of impact sound within a building. 
Table 1. Overview of the selected ceiling constructions from the investigations $[7,10,13]$.

\begin{tabular}{|c|c|c|}
\hline Ceiling Construction & & Structure \\
\hline Reinforced concrete & V1 & Reinforced concrete (140 mm thickness) \\
\hline \multirow{2}{*}{$\begin{array}{l}\text { Reinforced concrete slab with } \\
\text { floating floor }\end{array}$} & V1-A1 & $\begin{array}{l}\text { As V1, additionally with mineral wool } \\
(30 \mathrm{~mm}) \text { and cement screed }(50 \mathrm{~mm}) \text {, } \\
\text { according to Figure } 2\end{array}$ \\
\hline & V1-A4 & $\begin{array}{l}\text { As V1, additionally with polystyrene board } \\
(50 \mathrm{~mm}) \text { and cement screed }(50 \mathrm{~mm})\end{array}$ \\
\hline Wooden beam slab & $\mathrm{V} 2$ & $\begin{array}{l}\text { Wooden chip board }(22 \mathrm{~mm}) \text {, beams with } \\
120 \mathrm{~mm} \text { width } \times 180 \mathrm{~mm} \text { height (spruce); } \\
\text { mineral wool }(100 \mathrm{~mm}) \text {, wooden battens } \\
\text { with } 24 \mathrm{~mm} \text { width } \times 48 \mathrm{~mm} \text { height; gypsum } \\
\text { cardboard }(12.5 \mathrm{~mm})\end{array}$ \\
\hline $\begin{array}{l}\text { Wooden beam slab with floor } \\
\text { construction }\end{array}$ & $\mathrm{V} 2-\mathrm{A} 2$ & $\begin{array}{l}\text { As V2, additionally with wood fiber } \\
\text { insulation }(10 \mathrm{~mm}) \text { and gypsum fiber board } \\
(18 \mathrm{~mm})\end{array}$ \\
\hline $\begin{array}{l}\text { Wooden beam slab with floor } \\
\text { construction and suspended } \\
\text { ceiling }\end{array}$ & V2-A2-U1 & $\begin{array}{l}\text { As V2-A2, additionally with spacers with } \\
\text { elastic interlayers }(40 \mathrm{~mm}) \text { and two gypsum } \\
\text { boards }(2 \times 12.5 \mathrm{~mm}) \text {, according to Figure } 2\end{array}$ \\
\hline Solid timber slab & $\mathrm{V} 4$ & $\begin{array}{l}\text { Cross laminated timber made of spruce (CLT) } \\
(140 \mathrm{~mm})\end{array}$ \\
\hline $\begin{array}{l}\text { Solid timber slab with floor } \\
\text { construction }\end{array}$ & V4-A6 & $\begin{array}{l}\text { as } \mathrm{V} 4 \text {, additionally with separating layer, } \\
\text { infill }(60 \mathrm{~mm}) \text {, mineral wool }(30 \mathrm{~mm}) \text {, } \\
\text { separating layer, cement screed }(60 \mathrm{~mm})\end{array}$ \\
\hline $\begin{array}{l}\text { Solid timber slab with floor } \\
\text { construction and suspended } \\
\text { ceiling }\end{array}$ & V4-A6-U2 & $\begin{array}{l}\text { as V4-A6, additionally with spacers }(70 \mathrm{~mm}) \text {, } \\
\text { mineral wool }(60 \mathrm{~mm}) \text { and gypsum board } \\
(12.5 \mathrm{~mm}) \text {, according to Figure } 2\end{array}$ \\
\hline
\end{tabular}

Table 2. Comparison of the weighted impact sound levels $\mathrm{L}_{\mathrm{n}, \mathrm{w}}$ and associated frequency weighting values $\mathrm{C}_{\mathrm{I}}$ of the examined constructions.

\begin{tabular}{llccc}
\hline \multicolumn{1}{c}{ Ceiling Variants } & & $\mathbf{L}_{\mathbf{n}, \mathbf{w}}[\mathbf{d B}]$ & $\mathbf{C}_{\mathbf{I}}[\mathbf{d B}]$ & $\mathbf{L}_{\mathbf{n}, \mathbf{w}}+\mathbf{C}_{\mathbf{I}}[\mathbf{d B}]$ \\
\hline \multirow{3}{*}{ Reinforced Concrete Construction } & V1 & 76 & -11 & 65 \\
& V1-A1 & 41 & 15 & 56 \\
& V1-A4 & 50 & 3 & 53 \\
\hline \multirow{3}{*}{ Wooden Beam Construction } & V2 & 74 & 1 & 75 \\
& V2-A2 & 68 & 0 & 68 \\
& V2-A2-U1 & 63 & -2 & 61 \\
\hline \multirow{3}{*}{ Solid Timber Construction } & V4 & 88 & -4 & 84 \\
& V4-A6 & 57 & -1 & 56 \\
& V4-A6-U2 & 53 & 3 & 56 \\
\hline
\end{tabular}

If the raw ceiling constructions are acoustically improved by flooring and suspended ceilings, the improvement is recognizable by the single number value. However, the evaluation method according to DIN EN ISO 717-2 [15] only covers a frequency range between 100 and $3150 \mathrm{~Hz}$ which does not include the lower frequencies relevant for impact sound. Therefore, the spectrum adaptation term $C_{I}$ is used for the behavior of the constructions in the low-frequency range between 50 and $100 \mathrm{~Hz}$.

These types of constructive measures change the impact sound level of ceilings. In order to analyze this behavior, investigations were carried out at the Fraunhofer IBP which clarify the frequency-dependent performance of ceiling constructions according to DIN EN ISO 717-2 standards $[7,10,15]$. In the following, the wooden beam ceiling and the reinforced concrete ceiling are used as examples for the frequency-dependent comparison. The curves 
are shown in Figure 3. It is shown that both the reinforced concrete (V1) and the wooden beam (V2) raw ceiling construction have a high impact sound level in the low-frequency range below $250 \mathrm{~Hz}$. Nevertheless, the timber beam ceilings result is about $6 \mathrm{~dB}$ higher at $50 \mathrm{~Hz}$ and even $15 \mathrm{~dB}$ higher at $160 \mathrm{~Hz}$ than the reinforced concrete ceiling. This underlines the problem of increased low-frequency sound transmission in timber construction which is due to the lower density and therefore also the lower mass per unit area compared to reinforced concrete. The frequency curve for impact sound in reinforced concrete (V1) stagnates at about $70 \mathrm{~dB}$ above a frequency of $150 \mathrm{~Hz}$, while the curve for the timber beam ceiling (V2) decreases.

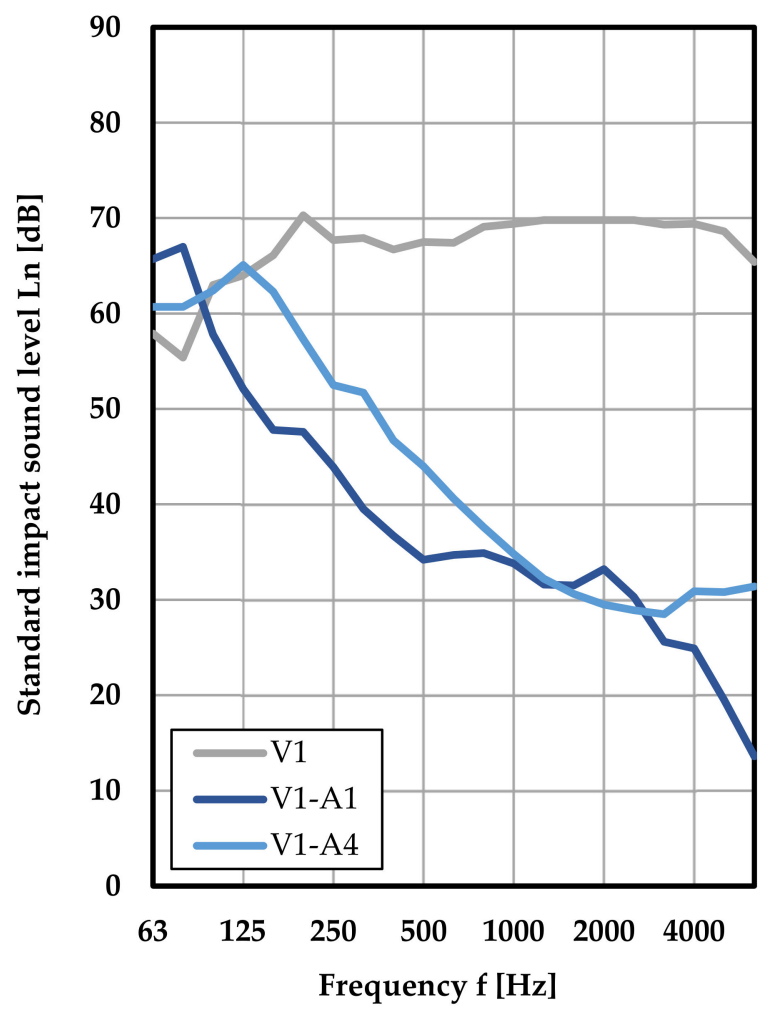

(a) reinforced concrete

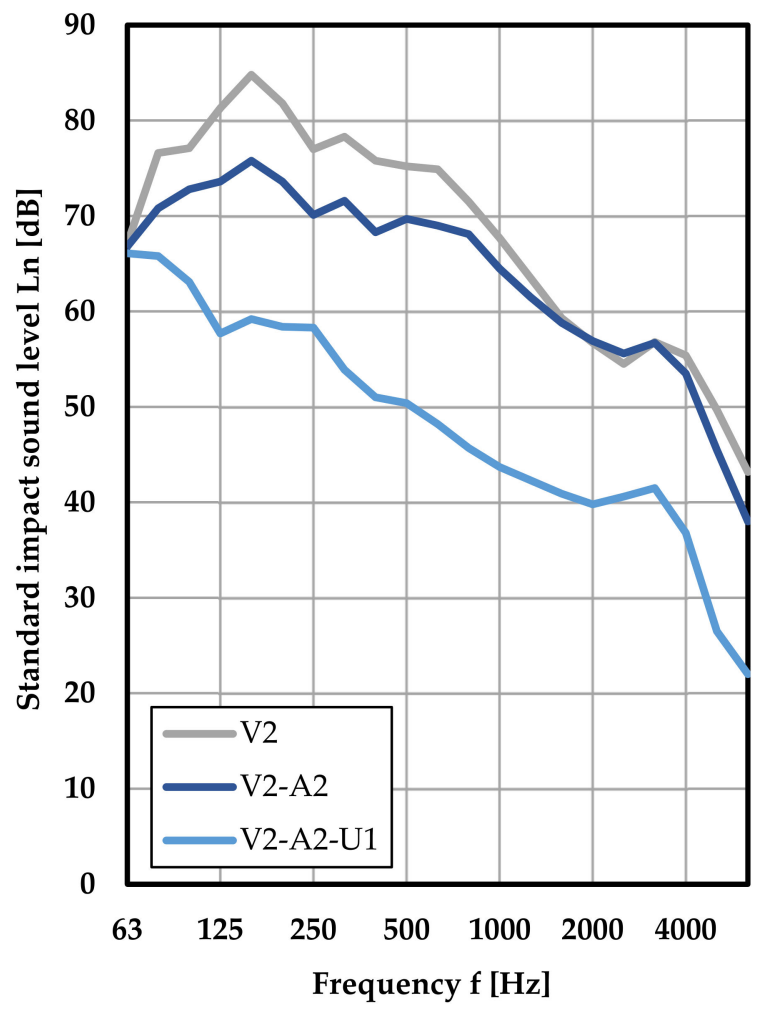

(b) timber frame

Figure 3. (a) Frequency response of reinforced concrete construction with different configurations $[7,10]$, (b) Frequency response of wooden beam ceiling with variations [7].

By constructive measures, such as a floor construction, depending on the design, clear differences in the effectiveness of the measures can be detected in the range between 63 and $125 \mathrm{~Hz}$ in Figure 3. Whereas improvements in the low-frequency range are particularly evident in the wooden beam ceiling due to constructive measures using cement screed in the floor structure (V2-A2), reinforced concrete ceilings may even deteriorate in this range under certain circumstances. This is due to the difference in the insulation materials used (V1-A1 and V1-A4). Between 50 and $100 \mathrm{~Hz}$, the optimization measures of the reinforced concrete ceiling (Figure 3a) even show a deterioration of the impact sound level by up to $12 \mathrm{~dB}$. These measures mainly show their effect in the higher frequency range. In the case of the wooden beam ceiling, the combination of floor construction improvements and a suspended ceiling (V2-A2-U2) has a great effect of reducing the impact sound level over the entire frequency curve. For example, the impact sound level at $125 \mathrm{~Hz}$ is reduced by almost $15 \mathrm{~dB}$. This is also visible in the spectrum adaptation term $\mathrm{C}_{\mathrm{I}}$ according to Table 2 by means of the negative sign and the resulting lower combined value $L_{n, w}$ and $C_{I}$ in the last column. 
The results of this part of the investigation have shown that the impact sound insulation in timber construction can be at a high level comparable to solid concrete constructions through a sensible conceptual design of the ceilings. The combination of floor construction measures and the use of a suspended ceiling is particularly effective at reducing impact sound. Further, the requirements according to DIN 4109-1 [23] are stricter for residential buildings than for office buildings. Depending on the room size and equipment, the expected impact sound insulation can differ by $+2 \mathrm{~dB}$ or $-2 \mathrm{~dB}$ [13], as sound protection does not depend on sound insulation alone. For this reason, the spectrum adaptation term $C_{I}$ should be considered when planning and designing buildings. However, there ensues the dilemma. The implications of design for impact sound on the economical and ecological aspects of construction will be discussed in the following section.

\section{Life Cycle Analysis}

The ecological consideration of materials and constructions as a supplement to the planning and design of buildings is gaining increasing importance under the aspect of holistic assessment. By applying the methodology of life cycle assessment, life cycle-based data can be generated and potential environmental impacts can be quantified. Further, the results can be used for ecological improvement and significantly influence the development of products and constructions.

The environmental impacts are quantified on the basis of the total energy input from renewable (PERT) and non-renewable resources (PENRT). Furthermore, the expected global warming potential (GWP), the acidification potential of soil and water (AP) and the eutrophication potential (EP) are investigated. For the balancing of the environmental impacts, the constructions according to Section 3 are used and the database ÖKOBAUDAT [19] is used as basis for the balancing. Thermal utilization was chosen as the end-of-life scenario, but without the credits from substituted electricity and heat generation from thermal utilization (Module D). According to the product category rules for wood-based materials as per standardized calculation rules [24], the energy for heat and electricity from natural gas combustion is substituted and the avoided emissions are credited. This results in high credits for wood components and can lead to a negative $\mathrm{CO}_{2}$ balance over the entire life cycle. This can give the impression that the processing and use of wood building materials is completely $\mathrm{CO}_{2}$ neutral or even negative. In fact, however, this is only the case in comparison to the currently defined state of the art and is therefore not considered in this study. The end-of-life scenario for wood and plastic components is set to incineration. All other components are set to a generic end-of-life which includes the separation and sorting as well as recycling, thermal utilisation or landfilling.

\subsection{Ecological Consideration of the Studied Constructions}

Constructions made of wood have a more beneficial global warming potential compared to constructions made of concrete (Figure 4). The differences become clear on the basis of the raw ceiling constructions. In this case, the reinforced concrete ceiling has twice as high values as the solid timber construction as seen in Figures 4 and 5. The higher $\mathrm{CO}_{2}$ emissions are caused by the costly and energy-intensive manufacturing process of concrete and cement. Due to their $\mathrm{CO}_{2}$ storage potential, wood-based construction materials have a lower environmental impact and thus a negative $\mathrm{CO}_{2}$ balance in the production phase. At the end of life, the stored $\mathrm{CO}_{2}$ is released. Figure 5 serves as an illustration. In this diagram, the global warming potential (GWP) of the investigated constructions is subdivided according to the life phases of production (module A1-A3) and end of life (module C). 


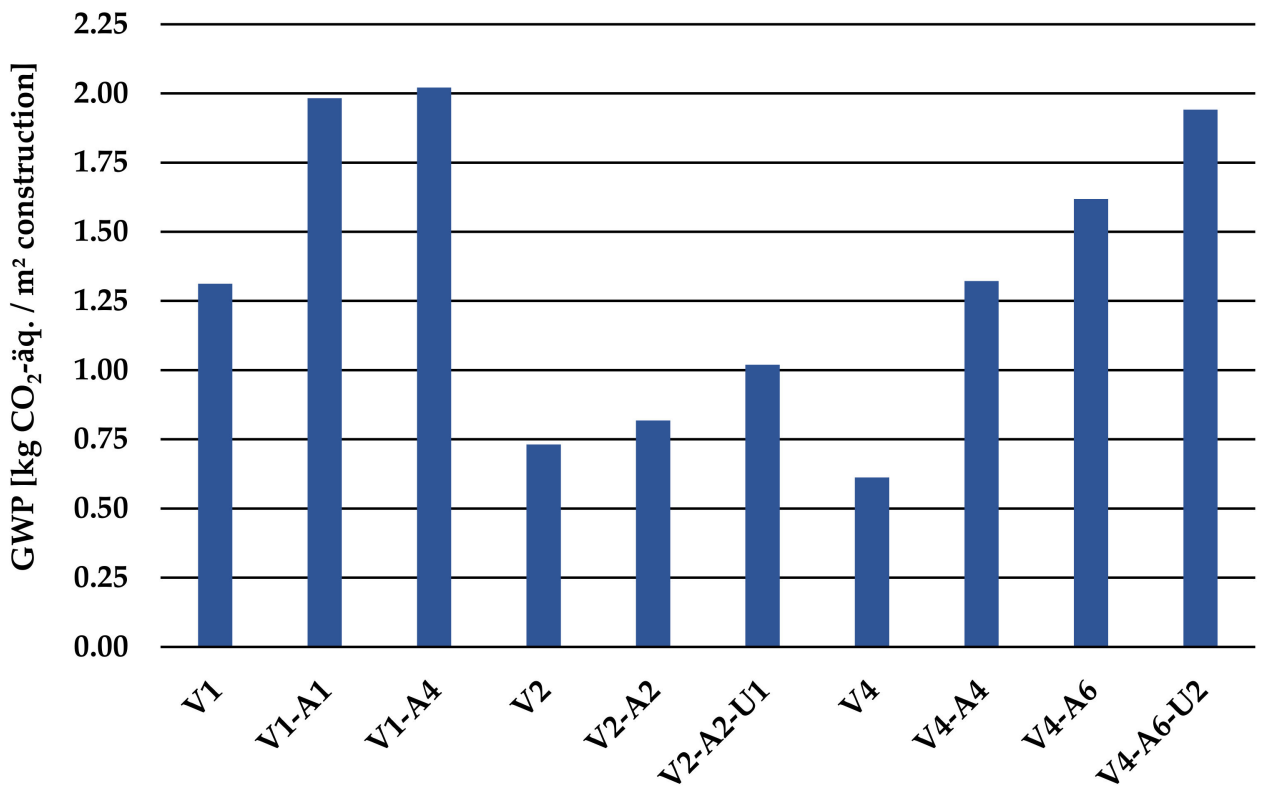

Figure 4. Global warming potential (GWP) in $\mathrm{kg} \mathrm{CO}_{2}$-äq. $/ \mathrm{m}^{2}$ of the exposed constructions.

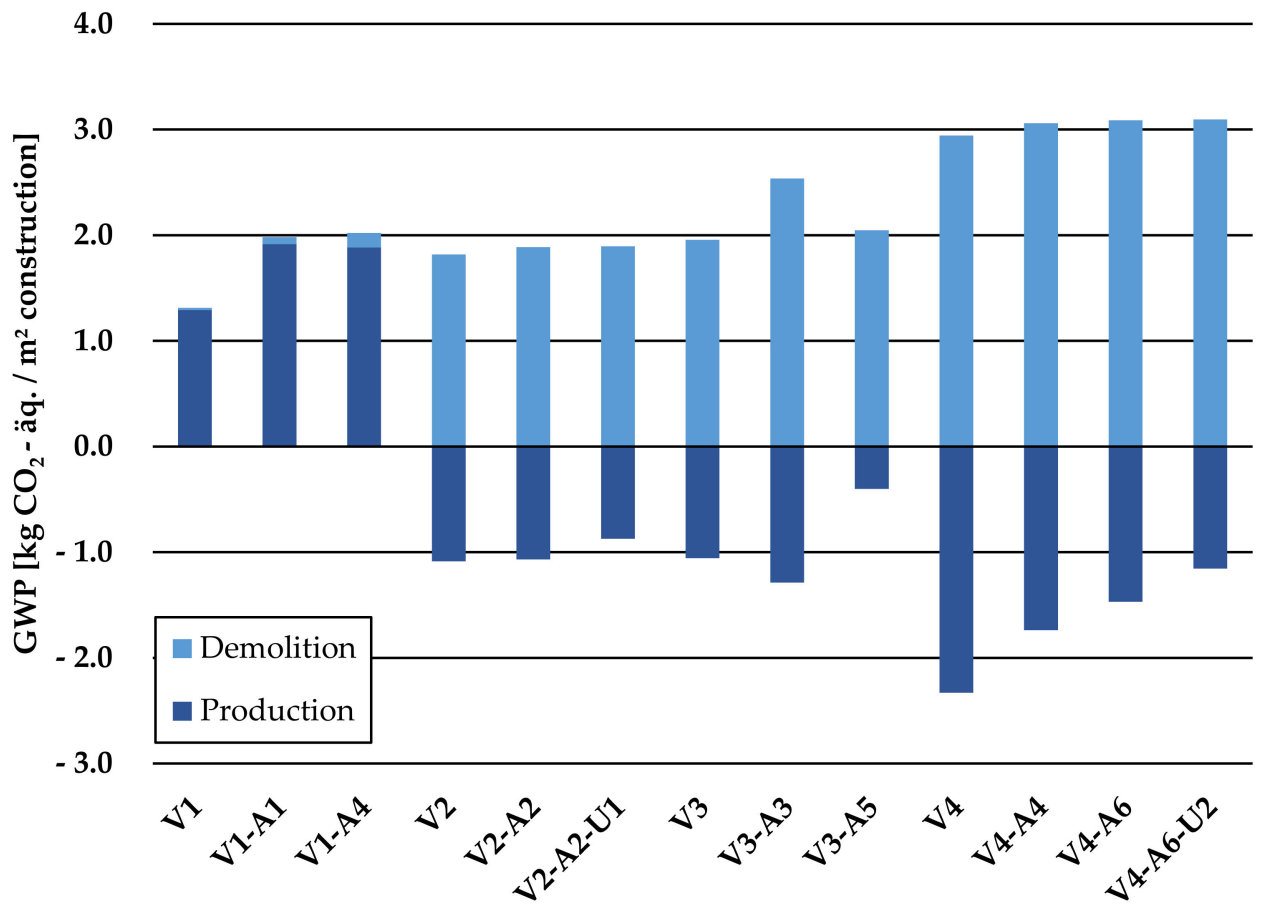

Figure 5. Global warming potential by life cycle phases of the exposed constructions.

In contrary to the global warming potential, the constructions made of wood have a higher share of primary energy consumption than concrete constructions (Figure 6). This could be due to the energy-intensive drying process in wood manufacturing and underlines the general problem of gray energy in the construction sector. In addition, the percentage of renewable primary energy in the case of concrete structures is only about $25 \%$, hence concrete constructions are inferior in terms of their environmental profile compared to timber constructions which is also due to the manufacturing process. With a percentage of around $70 \%$, the timber constructions achieve a higher ratio of renewable energy use, but offer less theoretical potential for optimization. 


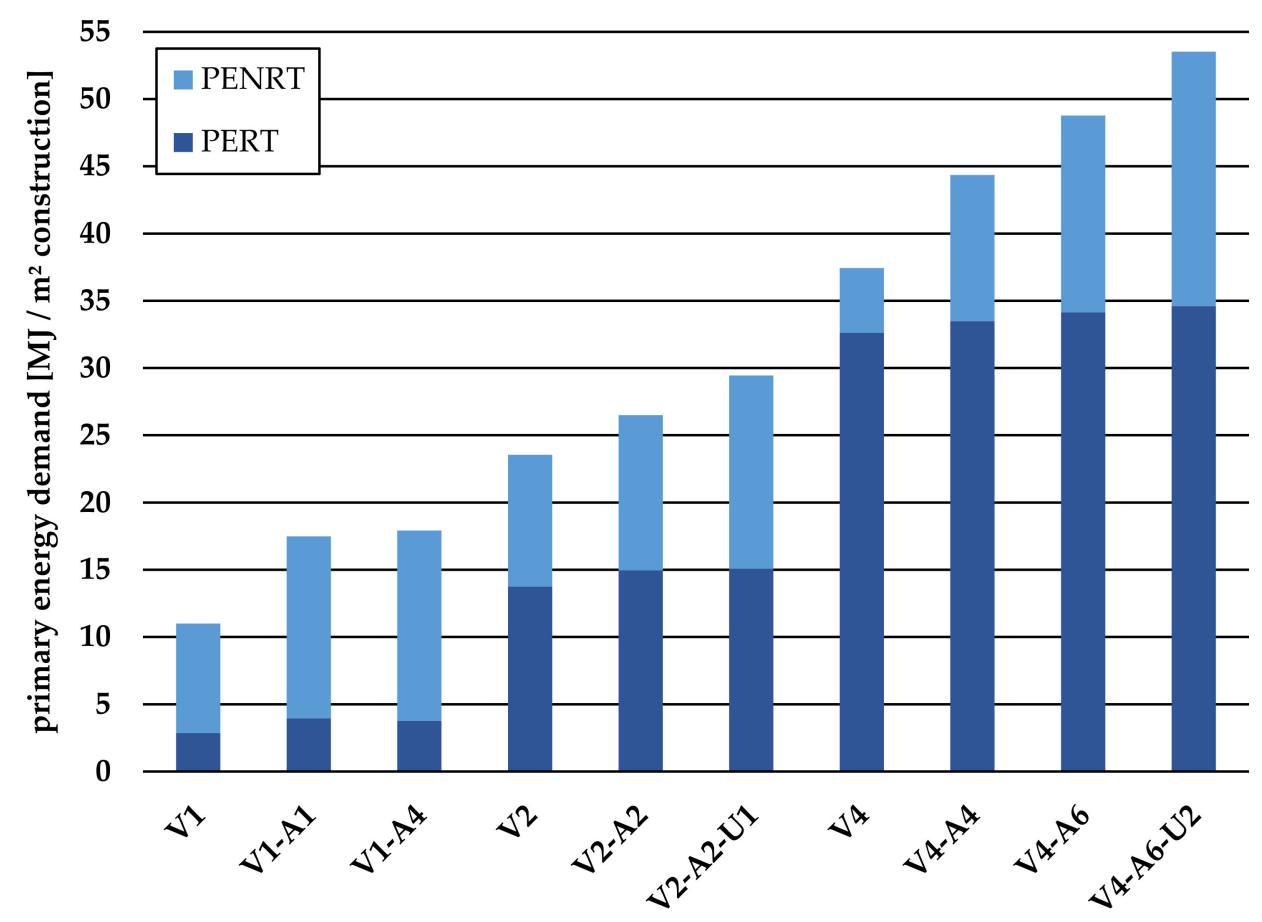

Figure 6. Environmental footprint of the studied construction methods in terms of renewable (PERT) and non-renewable (PENRT) primary energy demand.

Figure 7 shows the percentages of the respective total environmental impacts of the individual component layers for variants V1-A1 (reinforced concrete with mineral wool insulation and screed) and V4-A6 (solid wood with mineral wool insulation, screed and filling). In both diagrams it is shown that a significant part of the environmental impact is caused by the raw ceiling constructions. In the case of the timber construction, the screed has a larger share of the energy demand, as timber construction performs more beneficially than reinforced concrete according to the selected indicators and thus the comparative impact of the screed increases.

V1-A1

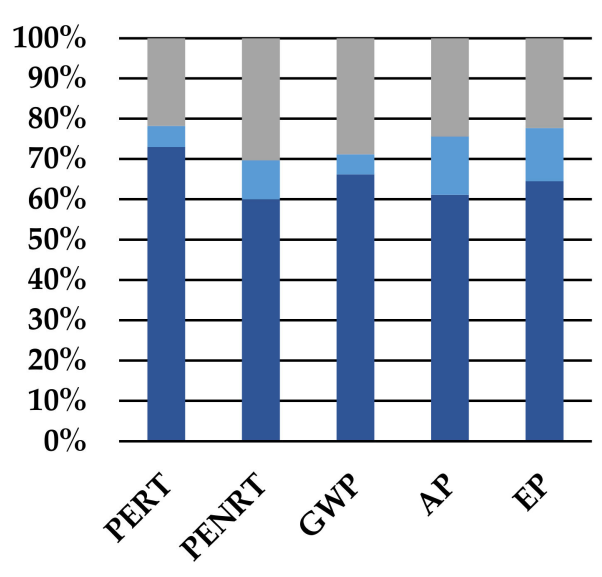

concrete mineral wool screed
V4-A6

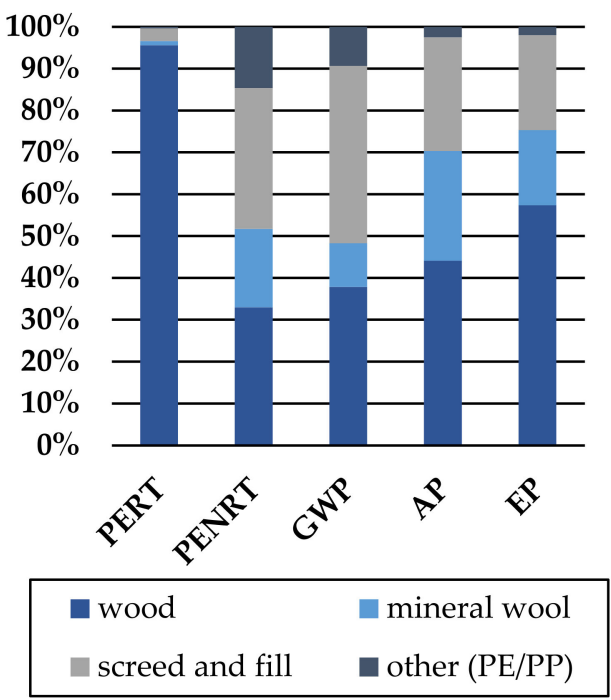

Figure 7. Comparison of environmental footprints of reinforced concrete construction V1-A1 and solid wood construction V4-A6. 
In order to discuss possible effects between the environmental impact and the acoustic performance, Figure 8 shows the corrected weighted impact sound level $\mathrm{L}_{\mathrm{n}, \mathrm{w}}$ on the primary axis and the GWP on the secondary axis. It can be seen that as the impact sound level of the constructions decreases, the GWP increases. This relation is particularly evident for the V4, V4-A6 and V4-A6-U2 variants (solid timber slab with improvement measures according to Table 1). A reasonable explanation for this effect is that the impact sound level, especially in timber construction, is lowered by increasing the mass, such as the application of filling and cement screed. This kind of increase in mass causes an increase in the environmental impact, in this case the GWP, while the materials remain the same.

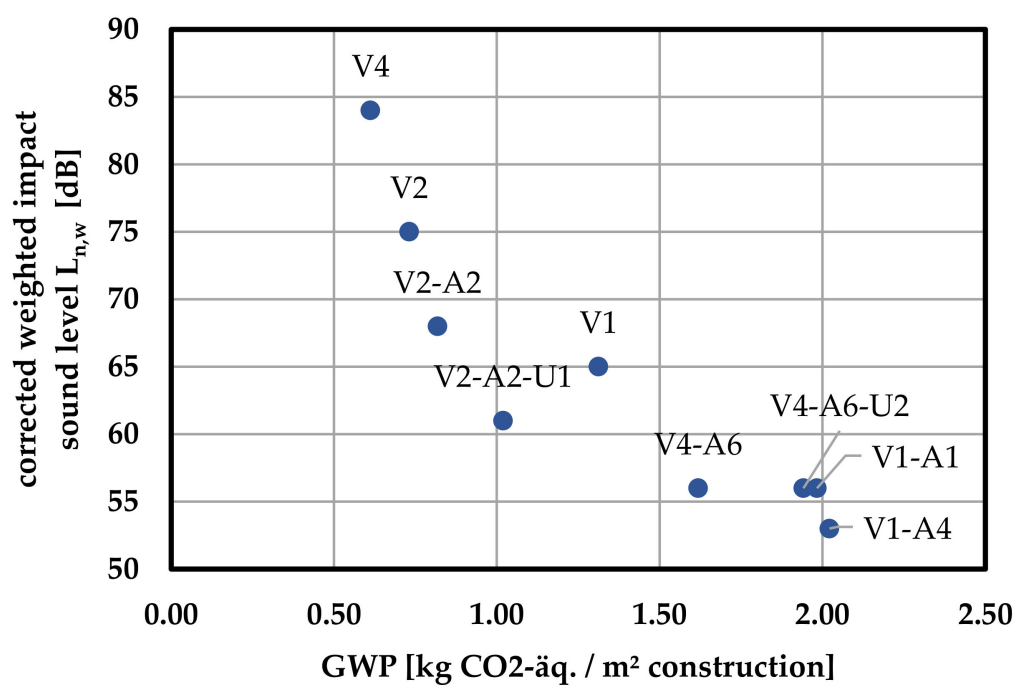

Figure 8. Relation of weighted impact sound level $\mathrm{L}_{\mathrm{n}, \mathrm{w}}$ (combined with frequency weighting value $\mathrm{C}_{\mathrm{I}}$ ) and global warming potential.

The effect of acoustic optimization also becomes evident when comparing the environmental footprint of a timber beam ceiling (V2-A2-U1) and a solid timber ceiling (V4-A6-U2), each with a floor construction and suspension. The solid timber ceiling is acoustically optimized with a cement screed and fill. The numbers show that the construction with cement screed and filling makes a significant contribution to the environmental impact. The measure can reduce the impact sound level by $5 \mathrm{~dB}(8 \%)$, but the GWP of the structure increases by $90 \%$. For a comparable impact sound level, the variant V4-A6 (without suspension) only shows an increase in GWP of about $60 \%$.

This comparison indicates the tendency that acoustic optimizations can result in relevant changes to the environmental profile and should therefore be selected and dimensioned with care.

\subsection{Optimization from an Ecological Point of View}

Optimizations, for example in the selection of an insulation material, must always be evaluated in the context of a suitable functional unit. This can be, for example, a specific impact sound level. By referring to a defined function, the material-specific properties are considered. Example: Insulation material A has a higher, volume-related GWP than insulation material B. However, since less material is required to fulfil a certain function, this results in a saving in the context of a comparable construction.

Furthermore, it makes sense to use constructions, building components and products as long as possible [25]. Already in the planning process and the optimization of components, reuse should be considered through constructive measures. This can be achieved, for example, through the standardization of elements or through easy adaptability [26]. 


\section{Summary and Discussion}

Based on the acoustic analysis of the examined constructions, the possibilities for improvement could be presented, considering the ecological aspects. The acoustic requirements for residential buildings are stricter than for office buildings. If the spectrum adaptation term $C_{I}$ is included in the evaluation of impact sound levels, the requirements for residential buildings are hardly met. Raw ceiling constructions made of both reinforced concrete and timber require constructive optimizations, as these cannot fulfil the minimum acoustic requirements. It becomes evident that the low frequencies are more problematic in the timber construction than in the reinforced concrete construction and this affects the acoustic quality of ceilings which underlines the challenge and relevance of acoustics in timber construction. It also highlights that if the acoustic measures are suboptimal planned and executed, they may not lead to any improvement and may even lead to a deterioration of the acoustic quality. In addition, the perceived acoustic quality of lightweight structures differs from solid structures which is why low-frequency sound transmission is the most frequent cause of complaints in timber and lightweight structures [27]. This underlines that the currently used evaluation systems for airborne and impact sound transmission should be extended to include low frequencies up to $50 \mathrm{~Hz}$ with the help of the spectrum adaptation term $C_{I}$ [15]. This aspect is further investigated at the Fraunhofer Institute IBP in order to develop a method for the psychoacoustic evaluation of the acoustic quality of buildings in timber construction [28].

The ecological assessment of this paper shows that timber constructions offer a GWP saving potential of up to $20 \%$ compared to acoustically comparable reinforced concrete constructions. Combined with the high $\mathrm{CO}_{2}$ storage potential of wood constructions, higher environmental qualities can be achieved if alternative solutions are found in the coming future that reduce energy consumption of the drying process during timber production and allow recycling of the building material to avoid the release of $\mathrm{CO}_{2}$ at the end of life. At this time, a significant part of the energy consumption is already covered by renewable energies which seems to be a reasonable approach in terms of reducing the climate impact in the sense of the greenhouse potential. For this reason, a comparison of different construction methods and the necessary optimization measures should be calculated and analyzed for the respective application. Furthermore, comparisons always have to be related to a functional unit, for example a specific acoustic performance, static load or heat transfer.

The LCA results in this study also have limitations, mainly because of the use of generic datasets. Generic datasets provide solid information in case a specific information is not available (e.g., origin or specific manufacturing processes). The downside is, that these often use statistical data and industry standards and therefore don't always represent the best or the worst-case scenario. With regard to the challenge of increasing the mass per unit area of wooden constructions, further assessments with low emission cement or recycling concrete will provide an additional view and take the technical progress in the corresponding processes into consideration. Additionally, the inclusion of module $\mathrm{D}$ with a realistic 2050 scenario (electricity grid mix and state of heat generation) would be valuable for the assessment as well.

For the use of wood as a building material in multistory residential construction, precise knowledge of the material properties and the structural-physical behavior is necessary [27]. With regard to thermal insulation and moisture performance as well as energy aspects, timber constructions can be comparable to reinforced concrete constructions [3]. In addition to the acoustic improvement of constructions, the ecological effects should also be considered when considering the development and planning goals. Depending on the design of the ceiling construction, the user comfort can be increased which is a great challenge especially in timber construction. Depending on the construction and improvement measure, a corresponding additional effort and related costs for planning and execution are to be expected. Since low-frequency sound transmission is the most frequent cause of complaints from users, especially in timber constructions, this represents the greatest problem for timber buildings. For this reason, well planned acoustic improve- 
ment measures are necessary in order to keep the additional costs as low as possible. It is important to ensure that the improvements show their effect in the desired frequency ranges and do not lead to an undesired deterioration of the overall construction.

\section{Outlook}

The above-mentioned aspects for the use of wood as a building material in multistory residential buildings are being further investigated as part of the sub-project RP3 of the Cluster of Excellence IntCDC [9] at the University of Stuttgart. The use of nature-based materials such as wood and the material-specific challenges with regard to their acoustic behavior are part of the current research questions. In particular, innovative approaches are being investigated to develop and implement alternative insulation and decoupling strategies to conventional solutions. In addition to the growing interest in research, there is also a need for the development of standards to promote dissemination in practice.

Modern manufacturing techniques and advances in materials production and manufacturing offer potential for cost reduction in this regard. Modular planning, which is gaining increasing attention in residential construction, also reduces both planning and construction time, which can have an impact on the costs incurred. In addition, digital tools and innovations, such as robotic fabrication, are increasingly gaining application in modern timber construction. Through innovative manufacturing methods, natural-based materials can be made more industrially suitable to further advance the research and development of both sustainable materials and constructions $[29,30]$.

The Cluster of Excellence Integrative Computational Design and Construction for Architecture (IntCDC) [31] at the University of Stuttgart is conducting research on this topic. The project is aiming to use the potential of digital technologies to rethink design, manufacturing and construction based on integration and interdisciplinarity in construction and architecture. Interdisciplinary research from areas such as architecture, civil engineering, building physics, and manufacturing and systems engineering will be used to create methodological foundations that will renew the design and construction process. New forms of efficient and sustainable building systems are to be developed through a higher-level integration of computational design and construction methods. The goal is to use the methodological insights and interdisciplinary results to contribute to the management of environmental, economic and social challenges that cannot be solved with current incremental approaches.

It is a challenge to consider acoustic and other building physical aspects of constructions, components and buildings in the context of holistic assessment. At the same time, however, it is precisely the holistic context that offers potentials for optimizing the environmental impacts [32]. These challenges are addressed in Collaborative Research Center 1244 entitled 'Adaptive skins and structures for the built environment of tomorrow' in sub-project D02 [33]. In addition, new methods for the planning of adaptive buildings and the exchange of information between the disciplines involved are being developed and tested [34]. The focus in the second funding period is, among other topics, on handling large amounts of data from simulation and calculation tools.

Author Contributions: T.M., D.B., S.A. and P.L. contributed to the conceptualization and methodology of this article. T.M. and D.B. were writing the original draft and edited this article. T.M. and P.L. have investigated the acoustic performance (Section 3). D.B. and S.A. have investigated the ecological aspects (Section 4). T.M. and D.B. contributed to the conclusions, summary and outlook and jointly wrote these sections. M.S. contributed resources and data to this work. P.L. was supervising and reviewing this article. The writing was reviewed and edited by T.M. All authors have read and agreed to the published version of the manuscript.

Funding: The research published in this article was supported by Deutsche Forschungsgemeinschaft DFG (DFG, German Research Foundation) under Germany's Excellence Strategy EXC2120/1-390831618, processed by the subproject RP3, and funded by the Deutsche Forschungsgemeinschaft (DFG, German Research Foundation)-Project-ID 279064222-SFB 1244, processed by the subproject D02. 
Institutional Review Board Statement: Not applicable.

Informed Consent Statement: Not applicable.

Data Availability Statement: All supporting background data for the LCA analysis comes from OEKOBAUDAT. The data published in ÖKOBAUDAT is publicly accessible and free of charge. The ÖKOBAUDAT platform is provided by the Federal Ministry of the Interior, Building and Community as a standardized database for the environmental assessment of buildings and construction [19].

Conflicts of Interest: The authors declare no conflict of interest.

\section{References}

1. United Nations Environment Programme. 2020 Global Status Report for Buildings and Constructions: Towards a Reo-Emission, Efficient and Resilient Buildings and Construction Sector; United Nations Environment Programme: Nairobi, Kenia, 2020.

2. Harder, N.; Klett, Y.; Park, S.; Leistner, P.; Middendorf, P. Bauphysikalische Untersuchung von Sandwichelementen. Bauphysik 2019, 41, 314-323. [CrossRef]

3. Müller, T.; Flemming, D.; Janowsky, I.; Di Bari, R.; Harder, N.; Leistner, P. Bauphysikalische und ökologische Potentiale von Gebäuden in Holzbauweise. Bauphysik 2021, 43, 174-185. [CrossRef]

4. Kaufmann, H.; Krötsch, S.; Winter, S. Manual of Multi-Storey Timber Construction. In Edition Detail, 1st ed.; Detail Business Information GmbH: Munich, Germany, 2018; ISBN 978-3-95553-395-3.

5. Späh, M.; Hagberg, K.; Bartlomé, O.; Weber, L.; Leistner, P.; Liebl, A. Subjective and Objective Evaluation of Impact Noise Sources in Wooden Buildings. J. Build. Acoust. 2013, 20, 193-213. [CrossRef]

6. Liebl, A.; Späh, M.; Leistner, P. Acoustics in Wooden Buildings: Evaluation of Acoustic Quality in Wooden Buildings: Listening Tests and Questionnaire Field Study; SP Technical Research Institute of Sweden: Borås, Sweden, 2014; ISBN 978-91-87461-66-8.

7. Späh, M.; Liebl, A.; Leistner, P. Acoustics in Wooden Buildings: Measurements in the Laboratory and in Single Family Houses; SP Technical Research Institute of Sweden: Stuttgart, Germany, 2014.

8. Forssen, J.; Kropp, W.; Brunskog, J.; Ljunggren, S. Acoustics in Wooden Buildings. Sate of the Art 2008: Vinnova Project 2007-01653; SP Sveriges Tekniska Forskningsinstitut: Stockholm, Sweden, 2008.

9. Cluster of Excellence Integrative Computational Design and Construction for Architecture. Multi-Storey Wood Building System: Research Project 3 (RP3): Computational Design, Engineering and Development of Digitally Fabricated Multi-Storey Wood Building System. Available online: https://www.intcdc.uni-stuttgart.de/research/research-projects/rp-3/ (accessed on 16 June 2021).

10. Leistner, P.; Schröder, H.; Richter, B. Gehgeräusche bei Massiv- und Holzbalkendecken. Bauphysik 2003, 25, 187-196. [CrossRef]

11. Blödt, A.; Rabold, A. Schallschutz im Holzbau: Grundlagen und Vorbemessung. In Holzbau Handbuch [Online], 1st ed.; 2019. Available online: https://informationsdienst-holz.de/fileadmin/Publikationen/2_Holzbau_Handbuch/R03_T03_F01_Schallschutz_ Grundlagen_Vorbemessung_2019.pdf (accessed on 25 January 2021).

12. Späh, M. ERA-WoodWisdom: Leise Holzgebäude für den Europäischen Markt (Silent Timber Build—Silent Timber Buildings for the European Market); Fraunhofer Institut für Bauphysik: Stuttgart, Germany, 2017.

13. Holzforschung Austria-Austrian Forest Products Research Society. Catalogue of Wood and Wood-Based Materials, Building Materials, Components and Component Connections for Timber Construction Covering Thermal, Acoustic, Fire and Ecological Performance Levels [Online]. 2020. Available online: https://dataholz.eu (accessed on 27 April 2021).

14. DIN German Institute for Standardization. DIN EN ISO 10140-5, Acoustics-Laboratory Measurement of Sound Insulation of Building Elements_Part 5: Requirements for Test Facilities and Equipment (ISO/DIS 10140-5:2020); German and English Version prEN ISO 10140-5:2020; Beuth Verlag GmbH: Berlin, Germany, 2020.

15. DIN German Institute for Standardization. E DIN EN ISO 717-2:2020-01, Acoustics—Rating of Sound Insulation in Buildings and of Building Elements_Part 2: Impact Sound Insulation (ISO/DIS 717-2:2019); German and English Version prEN ISO 717-2:2019; Beuth Verlag GmbH: Berlin, Germany, 2020.

16. DIN German Institute for Standardization. DIN EN ISO 14040:2009-11, Environmental Management-Life Cycle AssessmentPrinciples and Framework (ISO 14040:2006 + Amd 1:2020); German Version EN ISO 14040:2006 + A1:2020; Beuth Verlag GmbH: Berlin, Germany, 2009.

17. DIN German Institute for Standardization. DIN EN ISO 14044:2021-02, Environmental Management-Life cycle AssessmentRequirements and Guidelines (ISO 14044:2006 + Amd 1:2017 + Amd 2:2020); German Version EN ISO 14044:2006 + A1:2018 + A2:202; Beuth Verlag GmbH: Berlin, Germany, 2021.

18. Fraunhofer Institut für Bauphysik. GENERIS®[Software]. 2020. Available online: https://www.generis.live/ (accessed on 27 April 2021).

19. Deutsches Bundesministerium des Innern, für Bau und Heimat (BMI). Baustoffdatenbank ÖKOBAUDAT (Version 2021-I) [Database]. 2021. Available online: https://www.oekobaudat.de/datenbank/browser-oekobaudat.html (accessed on 27 April 2021). 
20. DIN German Institute for Standardization. DIN EN 15804:2020-03, Sustainability of Construction Works-Environmental Product Declarations-Core Rules for the Product Category of Construction Products; German Version EN 15804:2012+A2:2019; Beuth Verlag GmbH: Berlin, Germany, 2020.

21. DIN German Institute for Standardization. DIN 4109-32:2016-07, Sound Insulation in Buildings-Part 32: Data for Verification of Sound Insulation (Component Catalogue)—Solid Construction; Beuth Verlag GmbH: Berlin, Germany, 2016.

22. Di Bella, A.; Mitrovic, M. Acoustic Characteristics of Cross-Laminated Timber Systems. Sustainability 2020, 12, 5612. [CrossRef]

23. DIN German Institute for Standardization. DIN 4109-1:2018-01, Sound Insulation in Buildings—Part 1: Minimum Requirements; Beuth Verlag GmbH: Berlin, Germany, 2018.

24. DIN German Institute for Standardization. DIN EN 15804:2012+A2:2019, Sustainability of Construction Works-Environmental Product Declarations-Core Rules for the Product Category of Construction Products; Beuth Verlag GmbH: Berlin, Germany, 2019.

25. Allesch, A.; Laner, D.; Roithner, C.; Fazeni-Fraisl, K.; Lindorfer, J.; Moser, S.; Schwarz, M. Energie-und Ressourceneinsparung durch Urban Mining-Ansätze; Bundesministerium für Verkehr, Innovation und Technologie: Vienna, Austria, 2018.

26. Dodd, N.; Cordella, M.; Traverso, M.; Donatello, S. Level(s)_Ein Gemeinsamer EU-Rahmen Zentraler Nachhaltigkeitsindikatoren für Büro- und Wohngebäude: Teil 3: Durchführung von Leistungsbewertungen Mithilfe von Level(s) (Beta v1.0); Europäische Kommission: Luxembourg, 2017; ISBN 978-92-79-76907-8.

27. Green, M.; Taggart, J. Tall Wood Buildings: Design, Construction and Performance, 2. Auflage; Birkhäuser Verlag GmbH: Basel, Switzerland, 2020; ISBN 978-3-0356-1886-0.

28. Martin, N.; Müller, B. Erarbeitung Eines Psychoakustischen Klassifikationssystems für die Akustische Qualität von Einfamilienhäusern in Holzbauweise. Available online: https:/ /www.ibp.fraunhofer.de/de/presse-medien/kurzmeldungen/km_2020_07_ psychoakustisch-determinierte-schallschutzklassen.html (accessed on 29 July 2021).

29. Krieg, O.; Schwinn, T.; Menges, A. Neue Holztechnologien: Robotisch gefertigter Leichtbau. Holztechnologie 2015, 56, 20-26.

30. Wagner, H.J.; Alvarez, M.; Groenewolt, A.; Menges, A. Towards Digital Automation Flexibility in Large-Scale Timber Construction: Integrative Robotic Prefabrication and Co-Design of the BUGA Wood Pavilion. Constr. Robot. 2020, 4, 187-204. [CrossRef]

31. Cluster of Excellence Integrative Computational Design and Construction for Architecture. Cluster of Excellence Integrative Computational Design and Construction for Architecture: Shaping the Future of Architecture and the Building Industry through Truly Integrative Computational Design and Construction. Available online: https://www.intcdc.uni-stuttgart.de/ (accessed on 23 July 2021).

32. Harder, N.; Schlegl, F.; Albrecht, S.; Park, S.; Leistner, P. Bauphysikalische und ökologische Potenziale von adaptiven Leichtbaukonstruktionen. Bauphysik 2018, 40, 307-318. [CrossRef]

33. University of Stuttgart. D02-Life Cycle Engineering of Adaptive Skins and Structures. Available online: https://www.sfb1244. uni-stuttgart.de/en/project/d-ecological-aspects/d02-Life-cycle-engineering-of-adaptive-shells-and-structures/ (accessed on 21 June 2021).

34. Schlegl, F.; Honold, C.; Leistner, S.; Albrecht, S.; Roth, D.; Haase, W.; Leistner, P.; Binz, H.; Sobek, W. Integration of LCA in the Planning Phases of Adaptive Buildings. Sustainability 2019, 11, 4299. [CrossRef] 